\title{
ESTUDIO DE UN EXTRACTO DE MACA (Lepidium Meyenii Walp) CON ALTO CONTENIDO DE COMPUESTOS SOLUBLES
}

\section{STUDY MACA EXTRACT (LEPIDIUM MEYENII WALP) WITH HIGH SOLUBLE COMPOUNDS}

\author{
Vilma Julia Reyes de la Cruz ${ }^{17}$ y Emilio Fredy Yabar Villanueva ${ }^{18}$ \\ Facultad de Ingeniería en Industrias Alimentarias
}

\section{RESUMEN}

El trabajo de investigación fue desarrollado en el laboratorio de microbiología de alimentos de la Facultad de Ingeniería en Industrias Alimentarias de la Universidad Nacional del Centro del Perú con muestras recolectadas en la meseta de Bombón de la provincia de Junín. La investigación tuvo como objetivos, determinar las condiciones óptimas de obtención de un extracto a base de maca y evaluar sus características fisicoquímicas y microbiológicas. El extracto etanólico de maca fresca presenta mejor nivel de sólidos solubles, $23.1 \pm 1.37$ respecto al extracto etanólico de maca seca, $21.5 \pm 0.50$, indicando probablemente un mejor contenido de metabolitos secundarios de actividad biológica, con $\mathrm{pH} 6.06 \pm 0.28$ y \% de acidez $0.374 \pm 0.04$, mejores características fisicoquímicas respecto al extracto acuoso de maca frescay a los extractos de acuoso y etanólico de maca seca. El extracto etanólico de maca fresca presenta mayor actividad antimicrobiana contra Escherichia coli y es considerada como de moderada intensidad respecto a otros extractos vegetales con diámetro de inhibición de 7.5 $\mathrm{mm} \pm 0.14$. Estos resultados permiten sugerir una posterior purificación e identificación de las moléculas activas presentes en la maca tanto obtenidos en los solventes utilizados como en otros de menor polaridad.

Palabras clave: maca, extracto, actividad antimicrobiana

\section{ABSTRACT}

The research was developed in the laboratory of food microbiology at the Food Industry Engineering Faculty, of Universida Nacional del Centro del Peru with samples collected from Bombón hill in Junín. The research aimed to determine the optimum conditions for obtaining a maca extract and evaluate their physicochemical and microbiological characteristics. The ethanol extract of fresh maca showed better level of soluble solids, $23.1 \pm 1.37$, compared to ethanol extract of dried maca, $21.5 \pm 0.50$, indicating probably a better content of secondary metabolites of biological activity, $\mathrm{pH} 6.06 \pm$ 0.28 and $\%$ acidity $0374 \pm 0.04$, better physicchemical characteristics compared to aqueous extract of maca fresh and aqueous and ethanolic extracts of dried maca. The ethanol extract of fresh maca has greater antimicrobial activity against Escherichia coli and is considered moderate intensity with other plant extracts with inhibition diameter of $7.5 \mathrm{~mm} \pm 0.14$.

These results suggest a further purification and identification of active molecules present in the maca obtained in both solvents used as in other less polar.

Key words: maca, extract, antimicrobial activity

\section{INTRODUCCIÓN}

La maca (Lepidium meyenii Walp.), es un alimento funcional que se cultiva en los Andes peruanos desde el tiempo de los Incas, en altitudes comprendidas entre 3.800 a 4.500

\footnotetext{
17 vilmareyes23@hotmail.com

18 fredyyabar@yahoo.es
} 
metros sobre el nivel del mar. Es importante establecer los parámetros de extracción para lograr la estandarización del proceso, esto garantizará la calidad, rendimiento, seguridad y eficacia del extracto. La naturaleza química de la materia prima vegetal, las características del metabolito a extraer, la selectividad del solvente, la relación sólido-líquido, influyen en el rendimiento de extracción. El extracto vegetal obtenido se debe caracterizar en cuanto a: sustancias activas y marcadores, densidad, solventes residuales, sólidos totales, $\mathrm{pH}$, control microbiológico y volumen total. El trabajo plantea una metodología para la obtención de un extracto acuoso y etanólico de maca fresca y seca con el fin de utilizar su actividad biológica. Se propone un proceso de extracción, evaluación de sus características fisicoquímicas y su actividad antimicrobiana. La investigación tiene como objetivos, determinar las condiciones óptimas de obtención de un extracto a base de maca y evaluar sus características fisicoquímicas y microbiológicas.

\section{MATERIAL Y MÉTODOS}

Se realizó en el laboratorio de Microbiología de Alimentos de la Facultad de Ingeniería en Industrias Alimentarias de la Universidad Nacional del Centro del Perú. Básicamente se hizo un lavado, desinfectado, macerado en refrigeración por 24 horas con el solvente, agua o etanol, licuado y nuevamente un macerado en refrigeración por tres días para permitir una efectiva lixiviación. A los extractos acuoso y etanólico se realizó los siguientes análisis: sólidos solubles, $\mathrm{pH}, \%$ de acidez y actividad antibacteriana contra Escherichia coli.

\section{RESULTADOS Y DISCUSIÓN}

Contenido de humedad y materia seca de los hipocótilos de maca fresca y seca

Cuadro 1. \% Humedad y materia seca de los hipocótilos de maca fresca y seca amarilla

\begin{tabular}{|c|c|c|c|c|}
\hline Muestras & $\begin{array}{l}\text { Humedad \% } \\
\text { Maca fresca }\end{array}$ & $\begin{array}{l}\text { Materia seca } \% \\
\text { Maca fresca }\end{array}$ & $\begin{array}{l}\text { Humedad \% } \\
\text { Maca seca }\end{array}$ & $\begin{array}{l}\text { Materia seca \% } \\
\text { Maca seca }\end{array}$ \\
\hline 1 & 69.75 & 30.25 & 12.95 & 87.05 \\
\hline 2 & 68.92 & 31.08 & 11.92 & 88.08 \\
\hline 3 & 67.95 & 32.05 & 12.34 & 87.66 \\
\hline Promedio & 68.87 & 31.13 & 12.40 & 87.60 \\
\hline Desviación & 0.90 & 0.90 & 0.52 & 0.52 \\
\hline
\end{tabular}

Contenido de sólidos solubles en los extractos acuoso y etanólico de maca fresca y seca

Los resultados del cuadro 2, representa el nivel de sólidos solubles en los extractos en estudio.

Cuadro 2. Sólidos solubles en extractos de maca fresca y seca

\begin{tabular}{ccccc}
\hline Muestras & $\begin{array}{c}\text { Maca } \\
\text { fresca en } \\
\text { agua }\end{array}$ & $\begin{array}{c}\text { Maca } \\
\text { fresca en } \\
\text { etanol }\end{array}$ & $\begin{array}{c}\text { Maca seca en } \\
\text { agua }\end{array}$ & $\begin{array}{c}\text { Maca seca } \\
\text { en etanol }\end{array}$ \\
\hline $\mathbf{1}$ & 18.5 & 24.6 & 9,5 & 21,5 \\
$\mathbf{2}$ & 17.9 & 22.8 & 10,0 & 21,0 \\
$\mathbf{3}$ & 18.9 & 21.9 & 10,5 & 22,0 \\
Promedio & 18.43 & 23.1 & 10,0 & 21,5 \\
$\begin{array}{l}\text { Desviación } \\
\text { estándar }\end{array}$ & 0.50 & 1,37 & 0,41 & 0,50 \\
\hline
\end{tabular}

pH de los extractos acuoso y etanólico de maca fresca y seca 
El cuadro 3, permite predecir la estabilidad y efectividad de los extractos.

\begin{tabular}{ccccc}
\hline Muestras & $\begin{array}{c}\text { Maca } \\
\text { fresca en } \\
\text { agua }\end{array}$ & $\begin{array}{c}\text { Maca } \\
\text { fresca en } \\
\text { etanol }\end{array}$ & $\begin{array}{c}\text { Maca } \\
\text { seca en } \\
\text { agua }\end{array}$ & $\begin{array}{c}\text { Maca } \\
\text { seca } \\
\text { en } \\
\text { etanol }\end{array}$ \\
\hline $\mathbf{1}$ & 6.42 & 5.87 & 5,40 & 5,25 \\
$\mathbf{2}$ & 6.84 & 5.93 & 5.62 & 5,26 \\
$\mathbf{3}$ & 6.26 & 6.34 & 5.18 & 5,29 \\
$\begin{array}{l}\text { Promedio } \\
\text { Desviación }\end{array}$ & 6.51 & 6.06 & 5,40 & 5,27 \\
estándar & 0.30 & 0.20 & 0,22 & 0,02 \\
\hline
\end{tabular}

Cuadro 3. pH de los extractos acuoso y etanólico de maca fresca y seca Acidez de los extractos acuoso y etanólico de maca fresca y seca

El cuadro 4, muestra los valores de acidez de los extractos acuosos y etanólico.

Cuadro 4. \% de Acidez de los extractos acuoso y etanólico de maca fresca y seca

\begin{tabular}{ccccc}
\hline Muestras & $\begin{array}{c}\text { Maca } \\
\text { fresca en } \\
\text { agua }\end{array}$ & $\begin{array}{c}\text { Maca } \\
\text { fresca en } \\
\text { etanol }\end{array}$ & $\begin{array}{c}\text { Maca } \\
\text { seca en } \\
\text { agua }\end{array}$ & $\begin{array}{c}\text { Maca } \\
\text { seca en } \\
\text { etanol }\end{array}$ \\
\hline $\mathbf{1}$ & 0.242 & 0,387 & 0,340 & 0,346 \\
$\mathbf{2}$ & 0.284 & 0,393 & 0,262 & 0,326 \\
$\mathbf{3}$ & 0.226 & 0,342 & 0,318 & 0,329 \\
Promedio & 0.251 & 0.374 & 0.307 & 0.334 \\
$\begin{array}{l}\text { Desviación } \\
\text { estándar }\end{array}$ & 0.03 & 0.03 & 0.04 & 0.01 \\
\hline
\end{tabular}

Actividad antibacteriana de los extractos acuoso y etanólico de maca fresca y seca

El cuadro 5, representa la actividad antibacteriana de los extractos frente a Escherichia coli Cuadro 5. Diámetro en mm de inhibición de los extractos acuoso y etanólico de maca sobre Escherichia coli

\begin{tabular}{ccccc}
\hline Muestras & $\begin{array}{c}\text { Maca fresca } \\
\text { en agua }\end{array}$ & $\begin{array}{c}\text { Maca } \\
\text { fresca en } \\
\text { etanol }\end{array}$ & $\begin{array}{c}\text { Maca seca } \\
\text { en agua }\end{array}$ & $\begin{array}{c}\text { Maca } \\
\text { seca en } \\
\text { etanol }\end{array}$ \\
\hline 1 & 6.8 & 7.4 & 5.8 & 6.2 \\
2 & 6.9 & 7.6 & 5.7 & 5.7 \\
Promedio & 6.85 & 7.5 & 5.75 & 5.95 \\
Desviación & & & & \\
estándar & 0.07 & 0.14 & 0.07 & 0.35 \\
\hline
\end{tabular}




\section{DISCUSIÓN}

La biodiversidad se ha constituido en un recurso muy valioso para la humanidad y para preservarla es muy importante aprovecharla con la aplicación de técnicas razonables, compatibles con bioseguridad y en beneficio de la sociedad. Los metabolitos secundarios son todas aquellas moléculas activas generadas por diversas especies vegetales, son moléculas que no son necesarias para el crecimiento y la reproducción de las plantas, pero cumplen roles muy importantes en el reino vegetal, pueden suponer una ventaja competitiva considerable (1). Los extractos vegetales se han definido como un concentrado obtenido por tratamiento de productos vegetales con solventes apropiados, tales como agua, etanol, éter y otros, de elementos solubles, constituidos por una mezcla de principios activos y sustancias inertes que se producen de la totalidad o de partes de una planta fresca o seca (2). Los extractos acuosos son completamente solubles en agua y producen una solución transparente, algunas veces ligeramente turbia y los extractos alcohólicos son parcialmente solubles en agua y algunas veces son totalmente insolubles, tienen un excelente índice de disolución. El etanol es generalmente más eficaz para recuperar la mayoría de los metabolitos secundarios, las técnicas más utilizadas son por reflujo y por maceración en frío (3).

Los resultados de humedad y materia seca del cuadro 1, permiten realizar una formulación en base seca y en similar concentración para la preparación de los extractos de maca fresca y seca. La maca fresca y seca tienen componentes químicos diferentes, se sabe que un producto fresco desarrolla producto del estrés que pueda haber sufrido durante su periodo vegetativo hasta su maduración, pero un producto seco también desarrollo otros que se generan por la reactividad que tienen sus componentes durante la etapa post cosecha, pero tienen la ventaja de una mayor estabilidad. Los resultados del cuadro 2 , reporta un mejor promedio el extracto de maca fresca en etanol $23.1 \pm 1.37$ respecto a $21.5 \pm 0.50$ de sólidos solubles de maca seca y expresan el nivel de solubilidad de los principios activos e inertes en los solventes de extracción, existen diferencias entre los extractos de maca seca en agua respecto a los otros extractos. Presenta un mejor promedio el extracto de maca fresca en etanol demostrando que la maca fresca tiene biocomponentes que deben ser identificados. Un siguiente trabajo debe considerar el uso de solventes no polares para estudiar su actividad biológica y tener un espectro de aplicación mayor de la maca (4).

El pH es un parámetro muy importante en la evaluación de los metabolitos secundarios porque permite un nivel de disociación de las moléculas que efectúan la actividad biológica, normalmente es mejor adecuar al pH del material vegetal, además permite predecir el nivel de conservación de los extractos. Se demuestra que el etanol extrae mayor cantidad de sólidos solubles respecto al agua, lo cual se manifiesta en un valor de $\mathrm{pH}$ relativamente menor, $\mathrm{pH}$ de $6.06 \pm 0.28$, respecto al pH del extracto acuoso, $\mathrm{pH}$ 6.51. La razón puede explicarse a la diferente polaridad de ambos solventes y a los puentes de hidrógeno que son capaces de formar (2). Los valores de acidez pueden ser utilizados como un factor de grado de conservación de los extractos (cuadros 4 y 5). El extracto etanólico de maca fresca tiene un $\%$ de acidez de $0.374 \pm 0.03$. El cuadro 5 , demuestra una actividad antimicrobiana moderada sobre Escherichia coli, una Gram negativa sensible a los extractos acuoso y etanólico, probablemente debido a su pared celular menos compleja, capa simple y red de mureina delgada. No existe diferencia entre los extractos acuoso y etanólico de maca fresca, tampoco entre los extractos de maca seca en agua y de etanol, pero si entre los extractos de maca fresca respecto a los de maca seca. 
Presenta mayor promedio el extracto de maca fresca en etanol y es mucho más recomendable en la medida que pueda ser mejorada incrementando la concentración (3). La actividad antimicrobiana del extracto etanólico de maca fresca sobre Escherichia coli de $7.5 \pm 0.14 \mathrm{~mm}$ de diámetro de inhibición, demuestra la actividad biológica de la maca y deben ser investigados a nivel aplicativo, sobre todo utilizando las hojas que resultan eliminadas durante el proceso.

El extracto etanólico de maca fresca presenta mejor nivel de sólidos solubles, $23.1 \pm 1.37$ respecto al extracto etanólico de maca seca, $21.5 \pm 0.50$, indicando probablemente un mejor contenido de metabolitos secundarios de actividad biológica.

El extracto etanólico de maca fresca, $\mathrm{pH}$ $6.06 \pm 0.28$ y $\%$ de acidez $0.374 \pm 0.04$, presenta mejores características fisicoquímicas respecto al extracto acuoso de maca fresca y a los extractos de acuoso y etanólico de maca seca.

El extracto etanólico de maca fresca presenta mayor actividad antimicrobiana contraEscherichia coli y es considerada como de moderada intensidad respecto a otros extractos vegetales, diámetro de inhibición de $7.5 \mathrm{~mm} \pm 0.14$.

\section{REFERENCIAS BIBLIOGRÁFICAS}

Carratú, B. e Sanzini, E. Sostanze biologicamente attive presenti negli alimenti di origine vegetale. Ann Ist Super Sanità., 41(1), 7-16. 2005.

Gamarra S. Extracción de betaninas de las semillas de ayrampo (Opuntia soehrensii Britton \& Rose), evaluación de la capacidad antioxidante y compuestos. Fenólicos de los Extractos. Tesis (Ingeniero en Industrias Alimentarias). Lima, Perú. Universidad Nacional Agraria La Molina, Facultad de Industrias Alimentarias. 2003.

Gonzales G. La maca de la tradición a la ciencia Universidad Peruana Cayetano Heredia Lima. 2006.

Valentová, K., Buckiová, D., Kren, V., Peknicová, J., Ulrichová, J. and Simánek, V. The in vitro biological activity of Lepidium meyenii extracts. Cell Biol Toxicol., 22: 91-99. 2006. 